\title{
LEGALIZING BRIBE GIVING
}

\author{
MARTIN DUFWENBERG and GIANCARLO SPAGNOLO*
}

\begin{abstract}
A model of "harassment bribes," paid for services one is entitled to, is developed to analyze the proposal to legalize paying these bribes while increasing fines on accepting them. We explore performance as regards corruption deterrence and public service provision. Costs of verifying reports make the scheme more effective against larger bribes and where institutions' quality is higher. A modified scheme, where immunity is conditional on reporting, addresses some key objections. The mechanism works better against more distortionary forms of corruption than harassment bribes, provided monetary rewards can compensate bribers for losing the object of the corrupt exchange. Results highlight strong complementarities with policies aimed at improving independence and accountability of law enforcers. (JEL D73, K42, O17)
\end{abstract}

\section{INTRODUCTION}

Corruption remains an endemic problem in the developing world and has become a central political issue in many countries. Empirical work has considerably advanced our understanding of how widespread corruption is and how it can cause harm. ${ }^{1}$ Governments and agencies such as the World Bank have sponsored numerous anticorruption programs. However, regarding how to best fight corruption in practice, "research has lagged behind policy."2

* Many thanks to Husnain Ahmad, Pranab Bardhan, Kaushik Basu, Filippo Belloc, Jean Drèze, Giovanni Immordino, Elisabetta Iossa, Elena Paltseva, Debraj Ray, Jesper Roine, Danila Serra, and several referees for comments or discussions, as well as seminar participants at EIEF, IIES, University of Arizona, University of Gothenburg, UC Berkeley, LUISS (Rome), the Stockholm and the Toulouse Schools of Economics, the World Bank, SIDA, EALE 2012, and SITE 2012 Retreat. Dufwenberg thanks EIEF for hospitality and financial support. Spagnolo thanks the Wallander and Hedelius foundation (P2013-0162:1) for financial support.

Dufwenberg: Department of Decision Sciences and IGIER, Bocconi University, Milan 20136, Italy; Department of Economics, University of Arizona, Tucson, AZ; Department of Economics, University of Gothenburg, Gothenburg, Sweden CESifo Network. Phone +39-02-58365681, Fax +39 02 58365634, E-mail martin.dufwenberg@unibocconi.it

Spagnolo: SITE—Stockholm School of Economics, University of Rome Tor Vergata and CEPR, Box 6501, 11383 , Stockholm, Sweden. Phone +46 (8) 7369681, Fax +46 (8) 312422, E-mail giancarlo.spagnolo@hhs.se

1. See Svensson (2005) and Olken and Pande (2012) for excellent reviews.

2. The citation is from Banerjee, Hanna, and Mullainathan (2013, 1109). Olken and Pande similarly explain:
Recently, Kaushik Basu-chief economist then of the Indian government and now of the World Bank-proposed a specific approach. In Basu's (2011) pamphlet, "Why, for a Class of Bribes, the Act of Giving a Bribe Should Be Treated as Legal" he describes a society where bribery is "rampant ... a scourge that deserves to be banished," and proposes - for the case of "harassment bribes" that people pay to get services they are legally entitled to ${ }^{3}$ - the following policy:

\section{Legalize bribe giving, double the fine for bribe tak- ing, and make the bribe taker pay back the bribe if discovered.}

When a citizen bribes a bureaucrat, under traditional law the two become partners in crime.

"On the one hand, there has been a revolution in the measurement of corruption and this has, in turn, led to a blossoming of the academic literature on corruption. On the other hand, if we were asked by a politician seeking to make his or her country eligible for Millennium Challenge aid or the head of an anti-corruption agency what guidance the economic literature could give them about how to tackle the problem, we realized that, beyond a few core economic principles, we had more questions to pose than concrete answers."

3. This is often also called extortion. Think, for example, of persons getting passports they are entitled to, or of a qualified entrepreneur getting a license.

\section{ABBREVIATIONS}

BP: Basu's Policy

MBP: Modified Policy

SPE: Subgame Perfect Equilibrium 
They thus lack incentives to report the activity. Under Basu's policy (BP), which he deems "fairly radical," incentives are provided for the bribe giver to report the bribe taker. If this is foreseen, the bureaucrat would not accept the bribe in the first place. That is the key idea.

Will it work? A hot debate has raged in Indian and international press. The Economist appeared sympathetic. ${ }^{4}$ However, in some quarters, the proposal stirred outrage and commentators discarded it mainly on moral grounds. ${ }^{5}$ More tempered/thoughtful criticism has come from economists. Drèze (2011), in particular, wrote a penetrating comment arguing that Basu does not give adequate attention to some institutional and moral concerns which may change conclusions.

Basu's intriguing presentation is informal as is the heated debate it inspired. Perhaps one should not expect the issues to be easily settled through such discourse? The proposal is reminiscent of somewhat analogous tools used in other fields, such as leniency policies in antitrust and whistleblower protection and reward schemes against fraud and organized crime. Scholars who studied those measures have suggested they may be effective if well designed and administered, but counterproductive if details are not set right. ${ }^{6}$ Deeper understanding of the Pros and Cons of subtle legal rules may require careful scrutiny within a formal model.

In Section II, we develop a simple formal model to represent the scenarios Basu and his commentators care about as explicit games. By comparing equilibria, we draw conclusions regarding the conditions under which BP is likely to be effective. BP gets mixed, context-dependent grades and we highlight complementarities with other policies. The proposal works best if coupled with measures that increase the costs for bureaucrats of denying citizens what they deserve and that reduce the costs for citizens of getting justice. Verifying whether a bribe was paid entails costs which may deter reporting, hence $\mathrm{BP}$ works better against larger bribes. Inefficient or corrupt law enforcement increases these costs, so $\mathrm{BP}$ will be more effective if it is part of a wider

4. "Who [sic] to Punish," May 5, 2011. See also Paul Seabright's piece in Le Monde, May 24, 2011.

5. At times seemingly reflecting knee-jerk response rather than careful analysis; see, for example, P. Saniat's "Bribes: A Small But Radical Idea" in The Hindu (April 21, 2011,10 ), or the commentary in BBC's World Debate broadcast (World Economic Forum in Mumbai) of "Can India Beat Corruption?" (1:05 p.m., November 19, 2011, 47th min).

6. See Spagnolo (2008) for an overview. reform package that also fosters independence and accountability of the legal system.

In Section III, we take into account also the legal and moral considerations brought up by Drèze, revealing other problems related to BP. We propose a modified policy (MBP) that escapes many objections. The idea is inspired by leniency rules in antitrust. Rather than legalize bribe giving, only those who report having paid a bribe would be awarded legal immunity.

Extortionary harassment bribes are distortive when they are not paid, because a justified and presumably welfare-enhancing licence is then not issued. With other, arguably often more serious, forms of corruption distortions occur when bribes are paid, not otherwise. These are bribes to obtain something one is not entitled to. In Section IV, we consider how BP, and MBP, would fare with such bribes. At first glance, the results appear positive, but we highlight a credibility problem that is linked to the negative externalities entailed: After a briber blows the whistle, letting him keep the object of the corrupt deal (besides the bribe) may be politically unfeasible, hence not credible. However, we show that a monetary reward on top of the bribe may be an affordable solution to this problem as the reward must only match the briber's private valuation of the object, not the negative externalities it generates.

Section V contains complementary observations while Section VI sums up.

\section{A STYLIZED MODEL}

We now present some extortion/harassment bribe games that incorporate the implicit and explicit assumptions in Basu's note, focusing only on his original proposal. In later sections, we replace some assumptions with others that emerged in the debate as more realistic for some institutional environments, and consider a modified version of the proposal.

\section{A. Preliminaries}

The Basic Game. Consider the interaction between an entrepreneur $(E)$ and a civil servant $(S)$. The government has employed $S$ trusting him with the task of issuing licences to people like $E$ (imagine that another office has already certified that $E$ deserves the licence). However, it is within $S$ 's power to deny $E$ this treatment (or delay it). The bureaucrat may require a bribe 


\section{FIGURE 1}

Standard Law Enforcement

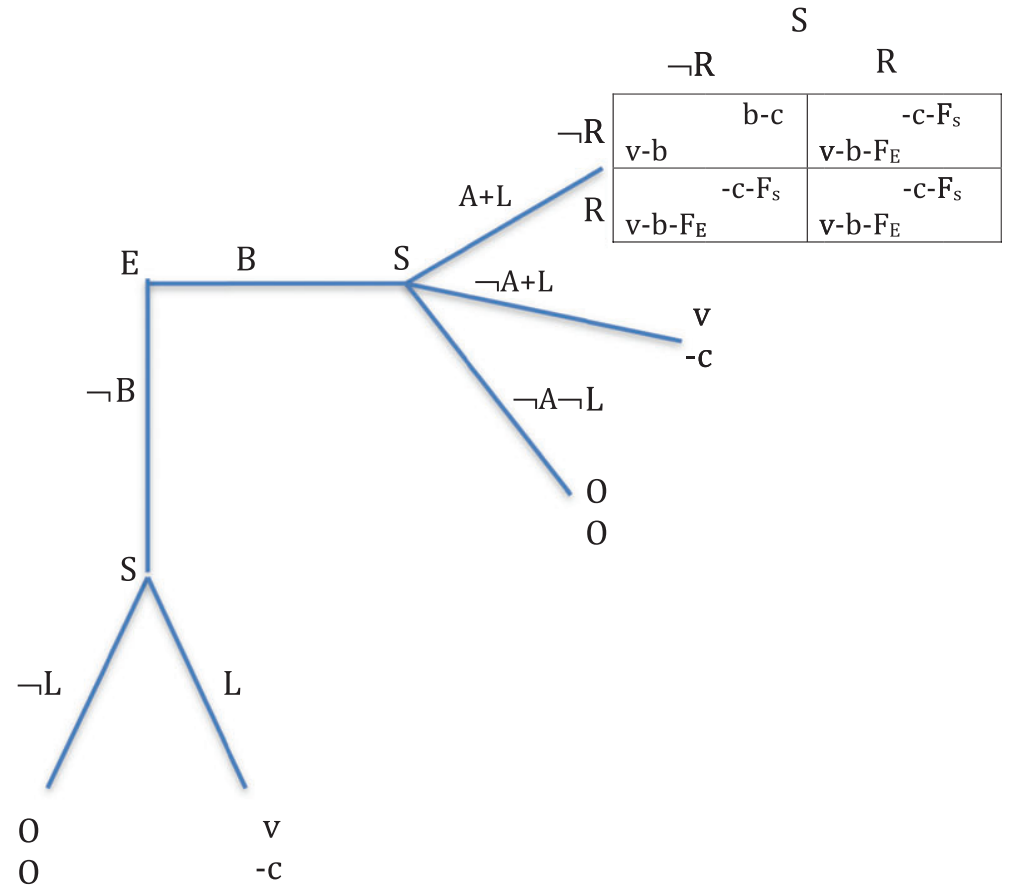

to issue the licence (on time) and $E$ may choose to offer $S$ a bribe. Giving and accepting bribes is illegal and subject to fines, but the practice is widespread and there is practically no chance of being caught unless an involved party reports the corrupt exchange to law enforcers. We assume that reporting to $S$ 's boss that a bribe was paid or that the licence was not being delivered (per time) would not be beneficial. ${ }^{7}$

Even with benevolent law enforcers, a party reporting a bribe will face some cost $C$ of proving that the claim is true (including the hassle of denouncing the illegal exchange, testifying, finding additional witnesses, requiring a bank to mark the banknotes or photographing them, etc.). We initially follow Basu and assume that these costs are smaller than the bribe, and to simplify notation we set $C=0$.

7. This captures situations where $S$ 's bosses are corrupt too, possibly sharing the bribes, or that there may be many excuses for a "delay" in the delivery of a licence (in contrast to the clear per se illegality of an established bribe). Including benefits from reporting would not change results if these gains are limited, and if $S$ 's boss applies pressure on $S$ to perform such an effect will be reflected by another parameter $(c)$, to be described shortly.
After $S$ has made it clear that a bribe needs to be paid to get the licence, the situation unfolds as described by the game in Figure 1 .

At the root $E$ either accepts offering a bribe $(B)$ or not $(\neg B) .{ }^{8}$ In the latter case, $S$ responds by issuing a licence $(L)$ or not doing so $(\neg L)$. If $E$ offers a bribe, then $S$ has three choices: not accepting the bribe and not issuing a licence $(\neg A \neg L)$; not accepting the bribe and issuing a licence $(\neg A L)$; and accepting the bribe and issuing the licence $(A L) .{ }^{9}$ If $E$ chooses $B$ and $S$ responds with $A L$ then the players simultaneously choose whether to report $(R)$ or not $(\neg R)$ the

8. We could add a preceding stage where $S$ chooses whether to require a bribe or where $E$ and $S$ negotiate so the bribe could be endogenously determined, but the game tree would get more complicated while results would not change much. Also, for public offices, it may make sense to assume that $E$ already knows (from the grapevine) that a bribe is expected and how large it should be.

9. We assume that when the bribe is accepted $E$ hands it over with one hand as he receives the licence in the other. Hence it is impossible for $S$ to accept the bribe and not issue the licence. This marks a difference relative to Buccirossi and Spagnolo's (2006) analysis of illegal exchanges where decisions are not simultaneous and need an enforcement mechanism in their own right. 
exchange of the bribe. As regards the payoffs, $b$ is the amount of the bribe, $v$ the value to $E$ of a licence, $c$ the cost to $S$ of issuing a licence, and $F_{E}$ and $F_{S}$ the fines to $E$ and $S$ if they are convicted for the corrupt exchange because of a report.

We assume that $F_{E}, F_{S}>v>b>0$ and that $b>|c|$ while $c$ may be either positive or negative. $c>0$ is relevant if $S$ has an opportunity cost of not shirking, say filling in paperwork rather than doing some other activity that benefits him (possibly playing a computer game). $c<0$ is relevant if denying $E$ a licence implies risk that $S$ is caught-in-the-act-and-fired. Of course, both considerations may apply in any given situation, so $c$ should be interpreted as reflecting their net effect. ${ }^{10}$ As the second consideration reflects ability to catch a shirking servant, we think of $c$ as reflecting how well organized government is (a lower value implying better organization). We view $c<0$ as the standard case but in extreme situations of poor state capacity the situation may be better captured by $c>0$.

The assumption that $v>b>c$ is key for furnishing scope for corruption. How is $b$ determined? We will not model that process, as most of our results do not depend on the exact level of $b$ (as long as $v>b>c$ ). Some results (especially in Section III) require $b$ to take a more specific value, in which case we offer related comments. We will then assume that $S$ has all the bargaining power in determining $b$, so that he can be viewed as unilaterally setting its level subject to relevant incentive constraints (this assumption makes sense especially if $S$, but not $E$, interacts repeatedly, which we shall consider our main focus).

Welfare. What game outcomes would be good or bad from society's point of view? To appreciate our approach, note first that $c$ is not a cost to care about for welfare purposes. Recall, $S$ is hired with the understanding that he should issue a licence to people like $E$. It is implicit that $S$ is adequately compensated and that the value to society of licensing is (much) higher than $c$. Hence, if $S$ fails to issue a licence to $E$ this is a bad outcome. Second, there may be welfare costs of bribes not reflected in the game's payoffs (as given). Why is there public debate about the (negative) effects of bribes and corruption even when they do not appear to distort allocations? The answer has to do with externalities. It may serve the public's interest, somehow, that people like $E$ get a licence

10. It appears unlikely that the two effects would cancel exactly, so we neglect the case of $c=0$. when they earnt it. That was our example above. Similarly, the occurrence of bribes may be bad. Why? Perhaps if $E$ has to bribe $S$ to get his licence, then this undermines civic morale. Perhaps, for example, it increases E's propensity to cheat when filling out his tax return. We shall not attempt any exact quantification of the societal benefits and costs associated with licences and bribes. Rather, we use two qualitative yardsticks as following:

- To what degree are bribes deterred?

- To what degree are licences issued?

Predictions. Section II.B considers the case where the game in Figure 1 is all there is to the interaction while Section II.C addresses the arguably more natural extension where $S$ plays repeatedly (the case where $S$ and $E$ are both repeat players is discussed in Section V). We treat the cases $c>0$ and $c<0$ separately, because predictions hinge crucially on the sign of $c$.

\section{B. One-Shot Interaction}

The Case of $\mathrm{c}>0$. Once the reporting subgame is reached (see Figure 1) each player has a (weakly) dominant choice not to report. Assuming each player thus chooses $\rightarrow R$, the game possesses a unique associated subgame perfect equilibrium (SPE): $S$ chooses $A L$ following $B ; S$ chooses $\rightarrow L$ following $\neg B$; and the best response for $E$ at the root is $B$. Compactly described, walking through information sets from left to right, for each player, the strategy profile in question can be written as $((B, \neg R),(\neg L, A L, \rightarrow R))$. The outcome: $E$ offers a bribe to $S$, who accepts it and issues a licence; no player reports the bribe. Is this good or bad? That depends. A bribe is paid, which is bad. However, a licence is issued, which in our context is good.

Consider now BP: Legalize bribe giving, double the fine for bribe taking, and make the bribe taker pay back the bribe if discovered. This policy leads to the game of Figure 2. ${ }^{11}$

If dominant choices are made in the reporting subgame ( $R$ for $E ;-R$ for $S$ ), this game has two SPE. Compactly described, as before, they are: $((\neg B, R),(\neg L, \neg A \neg L, \neg R))$ and

11. We assume the bribe is taken away from the bureaucrat if he is discovered, as most legislations prescribe this independent of how the bribe taker is discovered. Results would not change if instead the bribe were taken away from the bureaucrat only when it must be paid back to a bribe payer, as implicit in Basu's formulation. 


\section{FIGURE 2}

Basu Proposal

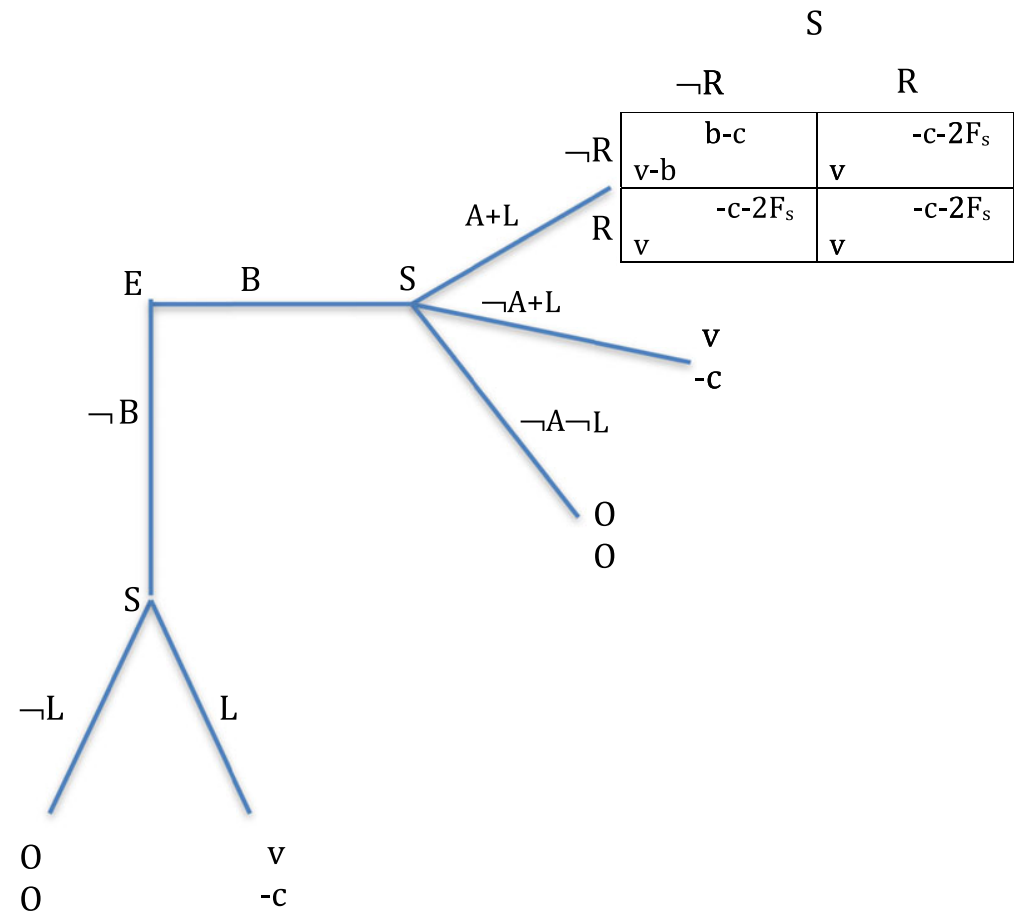

$((B, R),(\neg L, \neg A \neg L, \neg R)) . E$ may or may not offer a bribe, but the outcome is the same: $S$ does not accept any bribe and does not issue a licence. The welfare implications are flipped relative to the previous case. On the one hand, bribes disappear. On the other hand, no licences are issued. When the government is so poorly organized that $c>0, \mathrm{BP}$ is thus successful on corruption deterrence but reduces the number of licences issued.

The Case of $\mathrm{c}<0$. Back to Figure 1. Assuming that the dominant choices of $\rightarrow R$ are made, there is a unique associated SPE: $((\neg B, \neg R),(L, A L, \rightarrow R)) . E$ does not offer any bribe but $S$ issues a licence anyway, a good outcome on all fronts.

BP is now redundant, as the SPE path is the same when we move to the game in Figure 2: $E$ does not offer a bribe but $S$ issues a licence anyway. ${ }^{12}$

12. The overall solution changes off-path: the dominant choices in the reporting subgame are $R$ for $E$ and $\rightarrow R$ for $S$, so the game has two associated SPE: $((\neg B, R),(L, \neg A L, \neg R))$ and $((B, R),(L, \neg A L, \neg R))$.
The following proposition summarizes these results:

PROPOSITION 1. With costless reporting $(C=0)$ and one-shot interaction: If $c>0$ then BP deters bribes but leads to no licence being issued. If $c<0$ then $B P$ is redundant.

The appeal of this conclusion is questionable. The irrelevance result rests on $E$ being able to safely ignore $S$ 's bribe demands and still get a licence. In other words, BP is irrelevant only because the problem it aims to solve has been assumed away! We can think of many cases where harassment bribes are paid when $c<0$, arguably the most empirically relevant parameter range as $c>0$ refers to probably less common situations of more extreme bureaucratic inefficiency. What is missing from the picture? We believe the answer is that we have so far neglected important aspects that concern repeated play, and which change the conclusions. We show this next. 


\section{Repeated Interaction ("Long-Run S")}

Civil servants who deliver licences or perform analogous tasks are often around a long time. They may serve, or harass, many citizens/entrepreneurs, who are then likely to talk about their experiences. ${ }^{13} \mathrm{~A}$ more realistic setting to explore BP is therefore one in which $S$ is a "long-run" player who interacts over and again with new ("short-run") E's.

Assume the game analyzed in the previous section is played an infinite number of periods. In each period, $S$ interacts with a different $E$, who knows the history of play. Time is discrete and periods indexed by $t=1,2,3 \ldots$ Let $\delta$ denote the intertemporal discount factor, with $0<\delta<1$ (as usual, discounting alternatively captures situations in which the game is repeated a finite but uncertain number of times).

In such a "one-sided repeated game," perpetual play (following any history) of the one-shot equilibrium discussed in the previous section corresponds to a SPE. However, while short-run players are bound to play according to their static best-response strategies, the threat of perpetual reversion to a stage game Nash equilibrium can credibly be used to sustain other equilibria where the long-run player avoids her static best response (see Fudenberg, Kreps, and Maskin 1990). We focus on equilibria with as much bribery as possible, and explore whether BP changes patterns.

Long-Run $S, c>0$. If the bureaucracy is so inefficient that $c>0$, allowing $S$ to be a long-run player does not make bribery any less supportable as a SPE than in Section II.A. Perpetual play of the equilibrium of the one-shot game (starting at any history) is a SPE of the one-sided repeated game.

What happens if BP is introduced? As shortterm players are not able to commit, each $E$ has a dominant choice to report and get the bribe back. Therefore, $S$ accepts no bribe. As in the one-shot case, BP successfully deters corruption but has the drawback that no licences are issued.

Long-Run $S, c<0$. As flagged for at the end of Section II.B, allowing for a long-lived civil

13. Della Porta and Vannucci's (2012) study conversations between corrupt parties recorded by the police when a large Italian corruption network (Tangentopoli) was discovered in the 90s. The corrupt public officials were careful in developing, spreading, and maintaining a reputation for being reliable corrupt officials, who accept bribes without reporting bribery attempts to the police, and who reciprocate bribes with good performance and otherwise hardly perform at all (we are grateful to Elisabetta Iossa who brought DP\&V's work to our attention). servant may have dramatic effects when $c<0$. Perpetual play of the equilibrium from the oneshot scenario, where $E$ does not bribe and $S$ delivers the licence, is possible. However, as $S$ is a long-run player, as long as he is sufficiently patient, other equilibria emerge. We consider especially one where $S$ conditions his stage-game choices on whether or not he was bribed, namely:

- $S$ : Accept the bribe and issue a licence if $E$ offers a bribe. Do not issue a licence the first time some $E$ does not offer a bribe.

- Each $E$ : Offer the bribe if in the past $S$ always issued a licence every time a bribe was offered and did not issue a licence every time no bribe was offered. Do not offer a bribe otherwise.

The associated equilibrium exhibits an intriguing form of trigger-strategy combination, executed by the collection of short-run $E$ players: Along the equilibrium path each short-run $E$ takes into account that $S$ issues a licence iff he is bribed. This is sustained by the threat that if at any time a bribe were not offered and $S$ still delivered a licence then the "live" short-run players, from then on, would forever stop offering bribes and play would revert to perpetual repetition of the one-shot game equilibrium (with no bribes + licensing).

$S$ will play his part as long as the following incentive constraint is satisfied:

$$
-c \leq \frac{\delta}{1-\delta} b
$$

where $-c$ is $S$ 's short-run gain (note: $c<0$ so $-c>0$ ) from delivering a licence even if a bribe is not paid. On the right-hand side, we have the expected discounted loss of future payoffs caused by such a deviation. ${ }^{14}$

This simple inequality gives us several indications when to expect extortion to emerge in nonextreme situations: For example, if there is pressure on $S$ to perform (so that $-c$ is large) - for example if it is easy for $E$ to report to $S$ 's boss that the licence was delayed or withheld (and thereby to get the licence and have $S$ sanctioned) - then extortion is viable only for highly valuable tasks/licences (that justify a high $b$ ) or when $S$ is required to perform these tasks frequently (so that $\delta$ is high). Or consider projects

14. The per-period payoff of sticking to the equilibrium is $b-c$; the per-period payoff following a deviation is $-c$; the difference is $(b-c)-(-c)=b$, and the right-hand-side records present value. 
so valuable that they generate "grand corruption" (where $b$ is huge); it would be difficult to support such corruption if those opportunities were rare (so that $\delta$ were low).

Suppose now that this equilibrium is relevant and consider the effect of BP. ${ }^{15}$ As entrepreneurs are short-run players, reporting is a dominant choice if a bribe is exchanged. So, the best $S$ can do is to never accept a bribe but to always issue a licence anyway. BP thus works very well, both in terms of corruption deterrence and of efficiency. It makes it impossible to sustain equilibria with bribes and rationing by undermining $S$ 's ability to commit to a conditional licensing strategy, re-establishing the unique efficient static equilibrium.

The following proposition summarizes:

PROPOSITION 2. With costless reporting $(C=0)$ and $S$ a long-run player: If $c>0$, then $B P$ deters bribes but leads to no licence being issued. If $c<0$, then $B P$ deters bribes and generates licence delivery.

We find this last case particularly plausible, possibly most relevant and close to what Basu had in mind. We take it as the main benchmark to relate back to in the analysis to follow, although we will also keep track of what happens if $c>0$ or if $S$ is not a long-run player.

\section{ENRICHING THE MODEL}

In the games of Section II, the case for BP was rather positive. The proposal did very well, eliminating bribery and generating licences, in the more plausible scenario with $c<0$ and a longrun $S$. When instead the bureaucracy was so inefficient that $c>0$, BP worked less well, deterring bribes but also stopping delivery of licences (independent of whether $S$ was a long-run player). The results, however, relied on a set of simplifying assumptions. In the ensuing debate, several observers questioned some of these assumptions on the ground that they do not reflect the Indian reality. We now reformulate some of these concerns as parameter changes and explore how conclusions change. Our findings lead us to propose a modification of BP.

15. Equilibria without corruption are uninteresting here given that we are asking how to better fight existing/observed corruption.

\section{A. Costs of Reporting}

We have so far assumed that the costs for $E$ of reporting the corrupt exchange, and to get back the bribe, are negligible. This will in many cases be unrealistic as the costs of proving that a bribe of a given size was paid-including the time lost denouncing/testifying, marking banknotes or wiretapping the exchange-may be significant. In many situations where corruption is widespread among public servants, the law enforcement system is also inefficient or corrupt. As Drèze notes for India, a person who reports a bribe may expect "huge litigation costs, possible harassment, and little chance of getting justice."

Consider the case of costly law enforcement, where $E$ has to bear substantial burden to have $S$ convicted and the bribe returned. ${ }^{16}$ Assume that if $E$ reports he incurs litigation and harassment costs $C>0$, unless $S$ also self-reports/confesses. ${ }^{17}$ If these changes are incorporated to the pre-BP game of Figure 1, predictions do not change: For the one-shot interaction, we get bribes + licences when $c>0$ and no bribes + no licences when $c<0$. And for the one-sided repeated game with a long-run $S$, we get the analogous conclusions as those described in Section II.C.

With BP in operation, some predictions are affected though. Incorporating the mentioned parameter changes, we move from the game of Figure 2 to that of Figure 3.

If the cost of reporting is substantial, so that $C>b$, even after having paid a bribe and received the licence $E$ has no incentive to report. For the one-shot interaction, deriving predictions as usual, we get bribes + licences when $c>0$, and no bribes + no licences when $c<0$. For the one-sided repeated game with long-run $S$, we get the same conclusions as in Section II.C if the stage game were that of Figure 1. In other words, reporting costs larger than the bribe undo the effects that otherwise result from BP.

A twist to these conclusions may be noted. Assume that $S$ has all the bargaining power in determining $b$ (as appears natural in the one-sided repeated game scenario). Before $\mathrm{BP}$, in a bribery

16. In Section $\mathrm{V}(\mathrm{A})$, we discuss the slightly different case of corrupt law enforcement.

17. If $S$ also confesses, there is no defendant, corruption is proven by the confessions, and the case is closed with negligible litigation costs. We set $C=0$ to capture this and reduce the number of parameters in the matrix. Having a lower but positive $C$ would not change any of our conclusions. 
FIGURE 3

Basu + Costly Law Enforcement

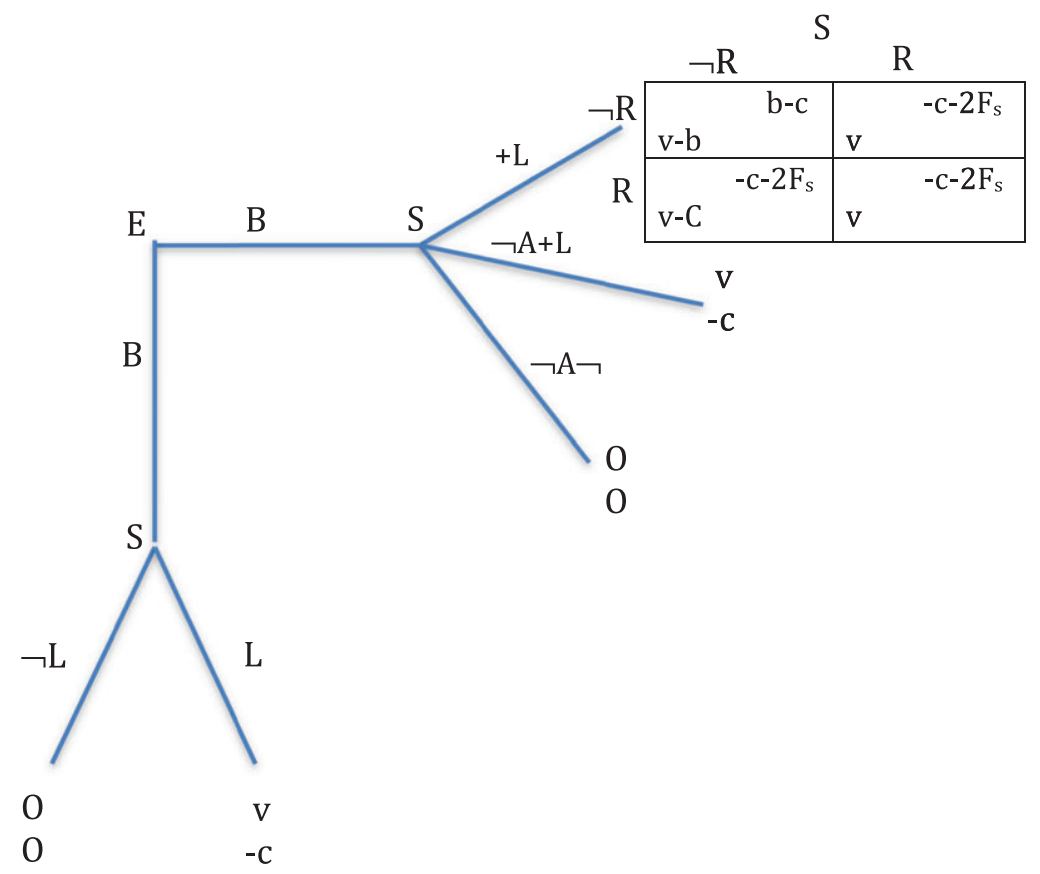

equilibrium, we would expect $b=v-\varepsilon$ where $\varepsilon$ is the minimum that $S$ needs to leave for $E$ to make him willing to bribe-for-a-licence. Now suppose that $C$ is moderate: $0<C<v-\varepsilon$. Does this mean that Drèze's critique does not apply? Not quite. $S$ may still be able to ensure that $C>b>0$ if $b$ is adjusted such that $0<b<C<v-\varepsilon$, thus reinstituting an equilibrium with bribery. BP would thus not be ineffective. Rather than eliminating bribes, it would lead to a reduction in the size of the bribe. ${ }^{18}$

We summarize:

PROPOSITION 3. When reporting costs are larger than the bribe $(C>b) B P$ is ineffective. When reporting costs are significant but smaller than the value of the licence $(0<C<v-\varepsilon) B P$ may not deter bribes but may reduce their size to satisfy $b<C<v-\varepsilon$.

18. If the discount factor is binding in the long-run $S$ case, we would expect the bribe to be set at the highest level satisfying $S$ 's incentive constraint with equality: $-c(1-\delta / \delta)=\bar{b}$. An intermediate level of $C<\bar{b}$ may then sustain a corrupt equilibrium even with BP in place, but with the bribe reduced to satisfy $0<b<C<\bar{b}$.
This suggests that $\mathrm{BP}$ is not that useful to fight small-scale, petty corruption. The proposal should work better against larger bribes, as these provide a stronger incentive for $E$ to incur the reporting costs $C$ in order to get back the bribe.

Is there any measure that could complement $\mathrm{BP}$, to help overcome the problems caused by a large $C$ ? One possibility may be to offer a reward, over and above bribe restitution, to reduce effectively $C$ and induce bribe givers to report. The high costs of legal action and of harassment from employers born by whistleblowers is precisely why several incentive programs implemented in the U.S. reward information with hefty monetary payments. But again, this might not work to fight the small bribes typical of petty corruption. The rewards and administrative costs of the program may be large before any deterrence effect materializes, which has to be financed by tax payers. This might generate unrest, and incentives for information fabrication and attempts to capture/blackmail innocent bureaucrats. So if reporting costs $C$ are sizable, policies directly aimed at increasing the efficiency of law enforcement institutions appear essential for BP to have beneficial effects. 


\section{FIGURE 4}

Moral Costs + Exogenous Conviction

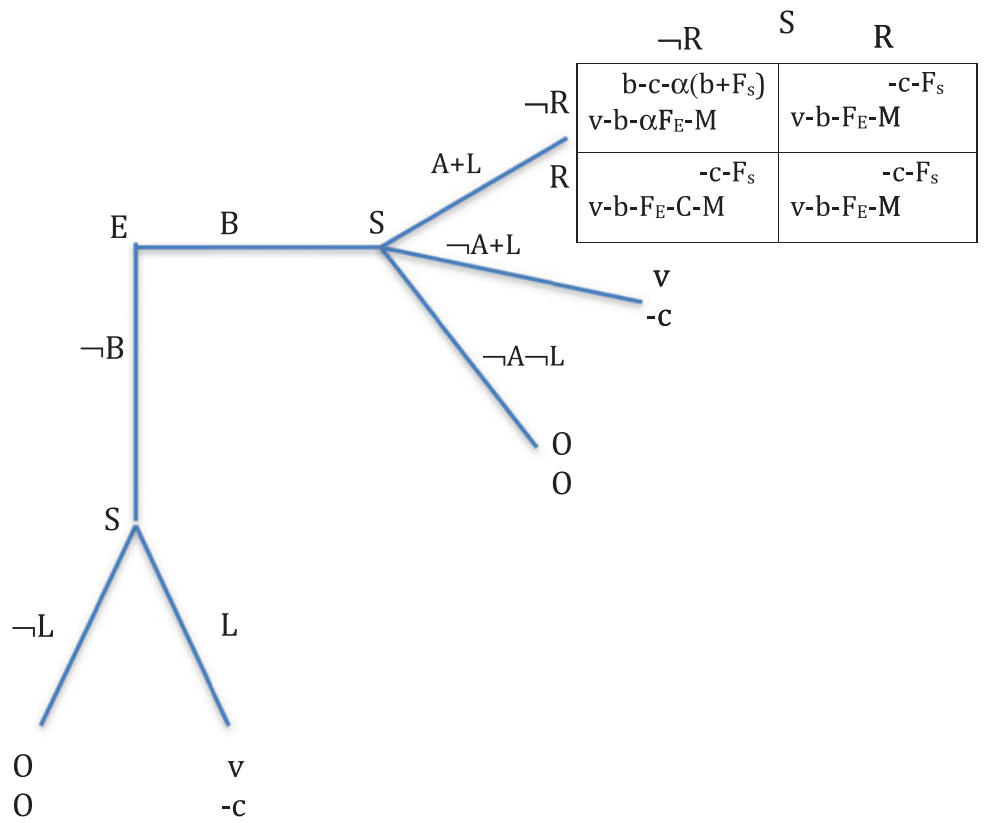

\section{B. The Moral and Legal Costs of Bribing and Not Reporting}

Until now we assumed that, apart from $b$ itself, there were no costs associated with paying a bribe (unless, of course, someone reported it). Drèze points out two reasons why this may lead to incorrect conclusions. First, there could be a possibility of being detected and convicted even without a report. Second, some people may suffer a moral cost when they illegally bribe. ${ }^{19}$ If so, Drèze argues, legalizing bribe giving may increase corruption. This is because $E$, who otherwise would offer no bribe, may now do so while planning on not reporting. Why? Drèze refers again to the litigation costs $C$ discussed in Section III.A.

To explore these aspects, ${ }^{20}$ let $0<\alpha<1$ be the probability of conviction if no party reports

19. An alternative hypothesis not considered by Drèze is that people feel outraged when forced to pay an illegal bribe for a service they should be entitled to, incurring an "outrage cost." If legalizing bribe paying reduced this cost, it could lead fewer people to resist bribe paying.

20. While we consider the presence of moral concerns we refrain from commenting on the morality of the proposal itself, which appears subjective. For example, some Indian commentators regard it as "fair" to consider harassment bribe payers as victims of bureaucrats (see, e.g., Business News, April 23, 2011). Drèze, by contrast, dislikes BP because it relies on "bribe givers being doubly corrupt: by giving a bribe, the bribe, ${ }^{21} M>0$ the moral cost of illegal bribe giving, and $C$ the expected cost of reporting and getting back the bribe (as before). Without BP, we get the game in Figure 4.

With $\mathrm{BP}$, paying a bribe is no longer illegal for $E$, so $F_{E}=0$. Moreover, it would arguably no longer be morally reprehensible to bribe, so $M=0 .{ }^{22}$ Finally, as in Figure 2, we assume that $E$ gets back the bribe if he reports. The game of Figure 4 changes into that of Figure 5.

and by stabbing bribe takers in the back as they blow the whistle." Judging negatively the act of turning in a fellow wrongdoer is common but not necessarily well grounded in ethics. It attributes the same positive value to legal and criminal cooperation, and the same negative value to betraying fellow citizens and mafia members. It is one of the reasons - together with violent revenge - why in some cultures it is difficult to find witnesses against criminal organizations.

21. If an outside party (a policeman) detects bribery without reports, could he be bribed to turn a blind eye? If so, might he get discovered, and face a similar situation "from the other side"? Basu, Bhattacharya, and Mishra (1992) explore such concerns, which we abstract from (taking $\alpha$ to be given). Basu et al. do not, however, let bribery parties self-report which implies (cf. their footnote 4) that it is irrelevant whether bribe giving is illegal.

22. We favor Drèze (and crispness) here; arguments could be made that moral costs remain positive with BP. 
FIGURE 5

Basu + Moral Costs + Exogenous Conviction

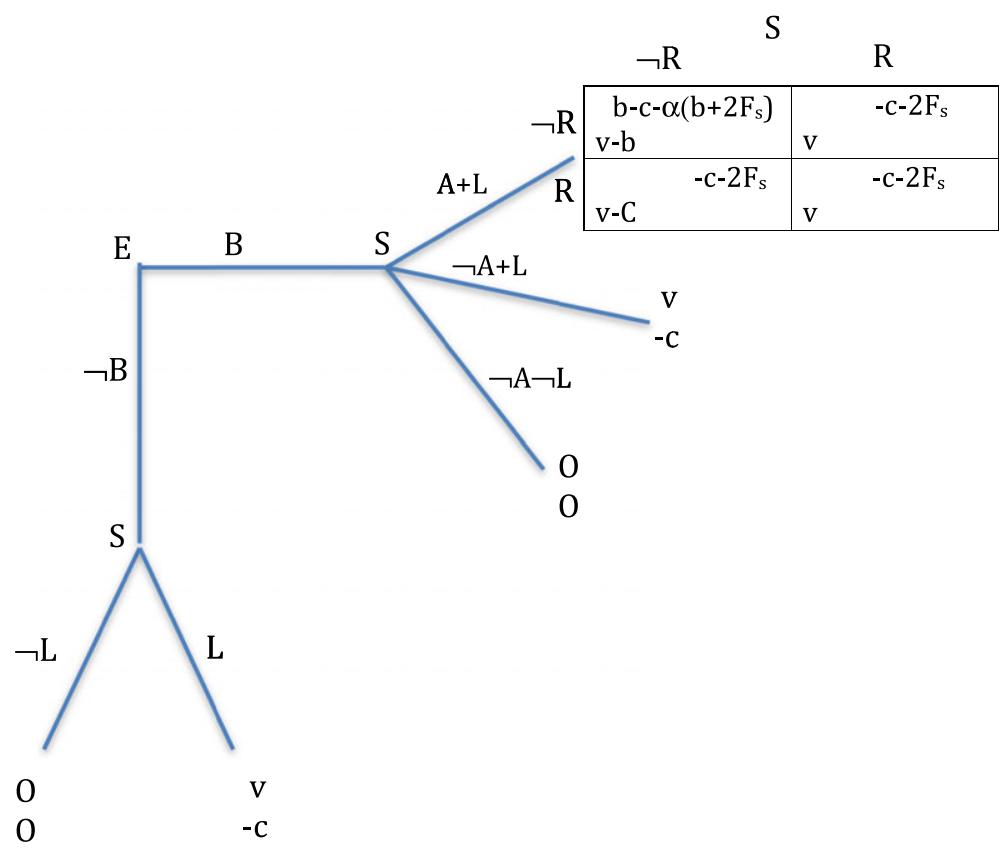

One-Shot Interaction. Without BP (Figure 4), no one reports, but if $\alpha$ and $M$ are high enough then $E$ does not wish to reach the reporting subgame regardless. We get no bribe + no licence when $c>0$ and no bribes + licence when $c<0$ - the same paths as with BP before, but now without BP. After introducing BP (Figure 5), when $c>0$ we move to a bribe + licence equilibrium, so that corruption increases with licences but only if $C \geq b$. When $b>C \mathrm{BP}$ induces $E$ to report and the no bribe + no licence outcome persists.

When $c<0$ there is no change (no bribe + licence).

Long-Run $S ; c>0$. Without BP (Figure 4), $E$ 's participation constraint (to play a bribe + licence equilibrium) will be satisfied if $v-b-\varepsilon-M-\alpha F_{E} \geq 0$, while $S$ 's participation constraint is satisfied if $b-c-\alpha\left(b+F_{S}\right) \geq 0$. Corruption is therefore viable only if the joint participation constraint

$$
\left(c+\alpha F_{S}\right) /(1-\alpha) \leq b \leq v-\varepsilon-M-\alpha F_{E}
$$

is satisfied; this cannot hold for sufficiently high $M, \alpha, F_{E}, F_{S}$, or $c$.
With BP (Figure 5), the range of bribes satisfying the joint participation constraint widens:

$$
\left(c+\alpha F_{S}\right) /(1-\alpha) \leq b \leq v-\varepsilon .
$$

It is thus possible that the pre-BP joint participation constraint cannot be satisfied while the new one can, a scenario which would appear to pave the way for Drèze's conclusion. However, to get the full picture one should take into account that, with $\mathrm{BP}$, if the bribe is too high then $E$ would report and $S$ would hence not accept the bribe. Put differently, as seen via Figure 5, $E$ will report when $v-C>v-b$, or $b>C$. To rule this out, the following incentive constraint must hold: $b \leq C$, or say $b \leq C-\varepsilon$ to break a tie. Summing up, Drèze's objection - that legalizing bribe giving makes people who previously did not bribe now do so-is valid only if the following inequalities all hold:

$$
\begin{gathered}
\left(c+\alpha F_{S}\right) /(1-\alpha)>v-\varepsilon-M-\alpha F_{E}, \\
\left(c+\alpha F_{S}\right) /(1-\alpha) \leq b \leq v-\varepsilon, \\
b \leq C-\varepsilon .
\end{gathered}
$$

Note also the following related observation. Suppose that $\left(c+\alpha F_{S}\right) /(1-\alpha) \leq v-\varepsilon-M$ 
$-\alpha F_{E}$, the pre-BP joint participation constraint holds. In this case, equilibrium bribery is possible before and after the introduction of BP, but the size of the bribes may differ. Sticking to the assumption that $S$ holds all the bargaining power, taking account of the stated inequalities, we get $b^{P R E}=v-\varepsilon-M-\alpha F_{E}$ as the pre-BP bribe and $b^{P O S T}=\min \{C-\varepsilon, v-\varepsilon\}$ as the bribe with BP implemented. Hence, we get $b^{P R E}<b^{P O S T}$ if $v-M-\alpha F<C$, and vice versa. In words: if $C$ is high enough, the bribe size increases with the introduction of $\mathrm{BP}$; if $C$ is lower, BP instead decreases the bribe size, and deters corruption altogether when $C \leq\left(c+\alpha F_{S}\right) /$ $(1-\alpha){ }^{23}$

Long-Run $S ; c<0$. Without BP (Figure 4), as in Section II, a bribe + licence equilibrium is sustainable using trigger strategies. The same joint participation constraint applies as above:

$$
\left(c+\alpha F_{S}\right) /(1-\alpha) \leq b \leq v-\varepsilon-M-\alpha F_{E} .
$$

To rule out that $S$ delivers a licence without a bribe the following incentive constraint must hold: ${ }^{24}$

$$
-c \leq \frac{\delta}{1-\delta}\left(b-\alpha\left(b+F_{s}\right)\right) .
$$

Now introduce BP (Figure 5). By setting $M, F_{E}=0$, the range of bribes satisfying the relevant joint participation constraints widens:

$$
\left(c+\alpha F_{S}\right) /(1-\alpha) \leq b \leq v-\varepsilon .
$$

$S$ 's incentive constraint remains as pre-BP, but for $E$ we have to add (as in the $c>0$ case)

$$
b \leq C-\varepsilon .
$$

The overall conclusions (regarding parameter regions under which Drèze's objection goes through or bribe sizes increase with BP) are analogous to those for the $c>0$ case above. When reporting costs $C$ are large, the size of the equilibrium bribe will increase with BP; if $C$ is low, BP decreases the bribe size, and deters corruption when $C \leq c+\alpha F_{S}$.

23. Similar bribe size remarks apply to the one-shot case, but appears less relevant as the idea that $S$ has all the bargaining power makes more sense if $S$ is a long-run player.

24. The left-hand side is $S$ 's short-run gain. The right-hand side is the present value of the loss thereafter: the per-period payoff of sticking to the equilibrium is $b-c-\alpha\left(b+F_{s}\right)$, the per-period payoff following a deviation is $-c$, so the difference is $b-\alpha\left(b+F_{s}\right)$.
We summarize these last findings:

PROPOSITION 4. With positive moral and legal costs of bribing, BP may increase the frequency of corruption if reporting costs $C$ are large, in which case it may also increase the size of the bribes. With low reporting costs BP either reduces the size of the bribe or deters corruption all together.

Two additional points can be brought home. First, Drèze's concerns about moral and legal costs of bribing do not bite per se. As implied by $E$ 's incentive constraint $b \leq C-\varepsilon$, it is necessary that $\mathrm{BP}$ - due to sufficiently high reporting costs - would not be effective in deterring corruption even if moral and legal costs were irrelevant. Second, bribes tend to be regressive. Imagine that individuals differ in their value of $C$, and that $S$ is experienced and gauges his coplayer's $C$ correctly and adjusts $b$. Individuals facing higher costs of reporting - most likely weaker, poorer persons unable to defend themselves from police harassment — would be asked to pay higher bribes (up to the constraints given above). This is probably a common aspect of corruption (cf. Hunt 2007), but it emerges quite naturally in our simple set up.

\section{A Slightly Modified Proposal}

Here is a new policy which is similar to BP, yet to a degree immune to the problems highlighted in Section III.B. We exploit an idea from leniency policies in antitrust under which participating in a cartel is not legal although immunity from fines is assured to whoever first reports the activity. We propose to grant $E$ similar immunity only if he reports having paid a bribe, and name this modified proposal MBP.

Apply that idea to the game in Figure 4. That is, if $E$ chooses $R$ then, in the corresponding row, remove $b$ and $F_{E}$. Make no change concerning $M$ and $\alpha$, bribing is still illegal and hence presumably morally costly, and on not reporting $E$ is still caught and fined with probability $\alpha$. We get the game in Figure 6.

Drèze's concerns about moral costs and exogenous probability of conviction now lose relevance. To see this, consider the analogs of the participation and incentive constraints discussed in Section III(B). For $S$, no payoffs change, so no constraints change. For $E$, recall first his briberyequilibrium participations constraint for the game of Figure 4: $c+\alpha F_{S} \leq b \leq v-\varepsilon-M-\alpha F_{E}$. Analogous reasoning as before makes it clear 
FIGURE 6

Leniency + Moral Costs + Exogenous Conviction

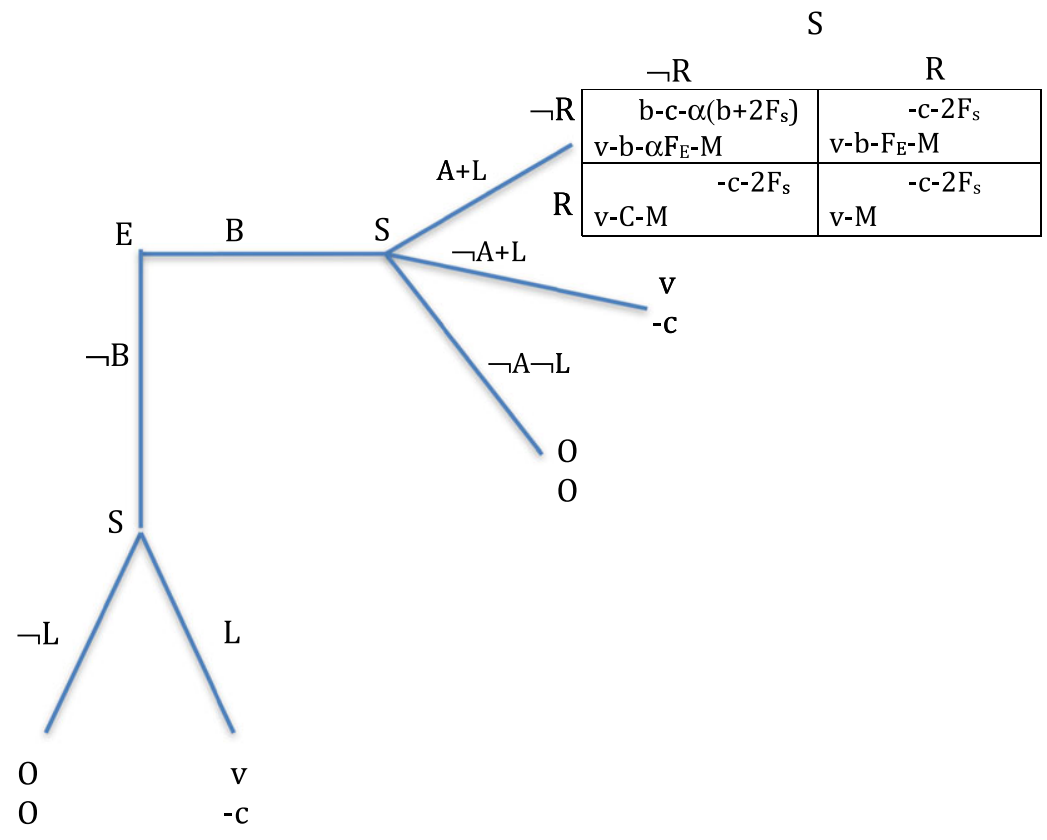

that this constraint does not change when considering instead Figure 6, so it is impossible that the preleniency joint participation constraint cannot be satisfied while the new one can. Next consider $E$ 's incentive to report; as seen via Figure 6, he will do this when $v-C-M>v-b-M-\alpha F_{E}$, or $b+\alpha F_{E}>C$. Hence, the relevant incentive constraint (to not report) is: $b \leq C-\alpha F_{E}$, or say $b \leq C-\alpha F_{E}-\varepsilon$ to break a tie. The analogous constraint from Section III.B was $b \leq C-\varepsilon$, so the new constraint implies the old one. All in all, unlike BP, the MBP shrinks the set of parameter constellations under which a bribe + licence equilibrium is sustainable. To emphasize:

PROPOSITION 5. MBP, a modified version of $B P$ such that amnesty (and bribe restitution) is conditional on reporting, prevents corruption from increasing because of the moral and legal costs of bribing (when $C$ is large).

A possible concern should be noted. Because bribe paying is not made legal under MBP, an entrepreneur who reports having paid a bribe will be a "guilty wrongdoer" when he enters the police station or court office to blow the whistle. By contrast, under BP, he would be innocent. One may therefore imagine that MBP enhances the scope to be harassed by the police. That is, with conditional leniency $C$ may increase (or be perceived to increase), relative to BP. So while softening Drèze's concerns about moral and legal costs, MBP may worsen his concern about inefficient law enforcement. That said, one should take into account that our scheme provides stronger incentives to report relative to $\mathrm{BP}$, as under MBP a reporter gains immunity from fines besides getting back the bribe. This additional gain may well compensate for the possible increase in reporting costs, at least if sanctions are robust. If so, with MBP incentives to report may actually be enhanced.

\section{OTHER FORMS OF CORRUPTION}

Basu circumscribed his proposal to harassment bribes/extortion, a practice often regarded as less damaging than forms of graft that generate undeserved advantages and hurt third parties. ${ }^{25}$ It is natural to wonder how extensions of BP

25. We do not entirely subscribe to this view, as in a financially and informationally imperfect world the "extortion tax" can prevent a lot of beneficial economic activity from taking place, thereby also distorting efficiency and harming third parties. 
would fare in regards to corruption more broadly. We initially planned to leave the issue for future research, but with the above analysis in hand we had an intriguing insight we now highlight. As a background, let us abstract from the complications of Section III-in which case BP and MBP have exactly the same effects - and summarize the results of the basic model of Section II in a table describing the welfare effects of these policies:

\begin{tabular}{lcc}
\hline & $\boldsymbol{c}>\mathbf{0}$ & $\boldsymbol{c}<\mathbf{0}$ \\
\hline One-shot game & Bribes $\downarrow$, licences $\downarrow$ & Ineffective \\
Long-run $S$ & Bribes $\downarrow$, licences $\downarrow$ & Bribes $\downarrow$, licences $\uparrow$ \\
\hline
\end{tabular}

Here "bribes $\downarrow$, licences $\downarrow$ " indicates that without $\mathrm{BP} / \mathrm{MBP}$ we had a bribes + licence equilibrium, which BP/MBP changes so that instead bribery ceases while no licence is delivered; "ineffective" means no change of the equilibrium, and so on. When $c>0$, the proposal thus deters corruption but inefficiently interrupts the provision of public service. When $c<0$, in the most plausible case in which $S$ plays repeatedly, the effects are all positive.

How do conclusions change if one instead considers situations with bribes for an illegal licence? To get at that, one must consider how the games of Section II change. The answer is: not at all! The payoffs for $E$ and $S$ remain as indicated, so strategic play is unchanged. The only aspect of the analysis that changes is that whereas before licences were good (from society's pointof-view) they are now bad. We can thus examine how BP/MBP fare using the above table, except that licences should now more appropriately be re-named "distortions."

\begin{tabular}{lcc}
\hline & \multicolumn{1}{c}{$\boldsymbol{c}>\mathbf{0}$} & $\boldsymbol{c}<\mathbf{0}$ \\
\hline One-shot game & Bribes $\downarrow$, distortions $\downarrow$ & Ineffective \\
Long-run $S$ & Bribes $\downarrow$, distortions $\downarrow$ & Bribes $\downarrow$, distortions $\uparrow$ \\
\hline
\end{tabular}

Actually, we are not done yet. The $c<0$ column must be irrelevant. Note that whereas before $S$ was hired to issue licences that people deserved, in the new situation the service performed for a bribe is illegal. So, $S$ must have been hired to do something else. If he nevertheless accepts a bribe and issues a licence then the two factors affecting $c$ discussed in Section II (opportunity cost of not shirking; risk of being caught-in-the-act-and-fired) point in the same direction; both ensure that $c>0$. So we can drop the rightmost column, and the reference to " $c>0$," and get:

\begin{tabular}{lc}
\hline & \multicolumn{1}{c}{$\boldsymbol{c}>\mathbf{0}$} \\
\hline One-shot game & Bribes $\downarrow$, distortions $\downarrow$ \\
Long-run $S$ & Bribes $\downarrow$, distortions $\downarrow$ \\
\hline
\end{tabular}

At first glance, this table appears spectacular. Basu proposed his policy solely with an aim on harassment bribes, and our analysis indicated that its blessings were a mixed bag. When we shift attention to the case of nonharassment bribes, the effect of BP/MBP becomes clearer and unambiguously good: bribes are eliminated, and no illegal services are performed.

However, this conclusion comes with a serious caveat. Consider the event that a bribe is given, that the illegal licence is awarded, and that $E$ reports to the government. We have implicitly assumed that $E$ gets to keep the licence. This is a strong assumption with distortionary corruption. The policy maker would stand ready, in principle, to not revoke licences which holders report to have acquired illegally! The game theorist in us objects that this does not matter. Along the equilibrium path, no licences are ever awarded. But the practical economist in us feels troubled. Consider an illegal licence that would seriously hurt third parties. For example, assume that a technically unfit entrepreneur is granted a state-sanctioned monopoly on the control and sale of water, or let the licence concern the right to convert the Grand Canyon to a driving range. Would it be ethically/politically defensible to sanction such arrangements, even counterfactually? Of course not.

The problem, however, can be solved with a further modification of the incentive scheme, introducing complementary monetary rewards that compensate entrepreneurs that report having paid a bribe for the loss of their distortive licence. Such rewards need only compensate for the private value of the lost illegal licence $v$, typically much less than the social harm $H$ produced by distortionary corruption. Consider, for example, procurement of public works. Unsound construction firms often pay bribes to obtain contracts to build schools, bridges, or hospitals (and then bribe again so that their low-quality work is not discovered). If the reporting briber loses the contract he loses the expected profits $v$ of executing that contract. If the contract is then re-allocated to a sound contractor, the public gain $H$ may be huge (not having jerry-built schools, bridges, or hospitals). It would then be optimal to pay a reward up to $H-v$ to avoid the distortions.

The following proposition reflects the comparison of the summary matrices above: 
PROPOSITION 6. If monetary rewards can be used to compensate for the loss of the licence/contract after reporting having paid a bribe, $B P / M B P$ will be more often welfare enhancing when used against distortionary forms of corruption than when used against harassment bribes.

To exemplify the potential scope of this proposal, consider Bertrand et al.'s (2007) study involving some bribery to obtain drivers' licences not deserved (e.g., because someone did not want to take driving lessons). Our proposal, based on the analysis in this section, would be that rewards for reporting a bribe should be commensurate to the cost of taking driving lessons and obtain the licence legally.

Monetary rewards are not a theoretical curiosity. They have been used for a long time to compensate whistleblowers for the large costs typically incurred when reporting information under the U.S. False Claim Act (a law originally introduced by President Lincoln to fight corruption in military procurement during the civil war!), and have recently been introduced in several other fields of law enforcement. ${ }^{26}$

A final remark for this section: in some situations, $S$ can choose among the two ways to extract bribes, for deserved or undeserved licences. That would be the case if the same civil servant-besides having the task of handing out licences - also were responsible for examining the case and deciding whether $E$ is eligible. One now has to be mindful that strengthening the fight of one type of corruption will not lead to substitution such that the other form of corruption increases. ${ }^{27}$ The finding of this section, that these policies can be effective against both forms of corruption, suggests that a coordinated introduction may be feasible and reduce this risk of substitution.

26. Monetary rewards were adopted in 2008 by the U.S. IRS to fight tax evasion, and introduced in 2011 in the Dodd-Frank Act to fight financial fraud. The administrative costs may be sizable (even if theoretically no reward should ever be paid in equilibrium if the scheme is well designed, staff needs be trained and allocated in case somebody reports to make the policy credible). To limit these costs, the programs establish a minimum size of the infringement below which they do not apply. This suggests that these schemes are better suited to fight the few large bribes of "grand corruption" than the small frequent bribes of "petty corruption."

27. A recent manuscript by Oak (2013) extends the analysis to address this intriguing aspect.

\section{ALTERNATIVE ASSUMPTIONS AND EXTENSIONS}

We now collect a series of observations and extensions that would have hampered flow earlier.

\section{A. Corrupt Law Enforcement}

In Section III.A we discussed the effects of exogenous law enforcement costs $(C)$ for agents that report having paid a bribe. What would happen if instead there was corrupt law enforcement? Assume that after the reporting stage, but before law enforcers establish whether or not corruption occurred, the parties can offer new bribes to affect the verdict. $E$ can offer a new bribe $b_{E}^{*} \geq 0$ to law enforcers to convict $S$ and get back the original bribe; $S$ can offer a bribe $b_{S}^{*} \geq 0$ to have the law enforcers falsely declare there were no corruption. Suppose this bribing competition takes the form of an English auction, and that law enforcers have some cost-of-lying denoted by $\pi$ (possibly because there is some small chance they will be indicted). Then $S$ will win the competition and be declared innocent if he is willing to pay more than $\pi$ in addition to the highest bribe that $E$ is otherwise willing to offer; $S$ is then convicted and $E$ obtains the original bribe $b$ back (but of course not the new bribe $b_{E}^{*}$ ).

Assume that at this bribing competition stage any preceding cost of reporting $(C)$ is sunk and does not reduce $E$ 's willingness to pay (our conclusions would be strengthened otherwise). $E$ is willing to pay up to $b$ to have the bribe back after a conviction of $S$. In case of conviction, $S$ will have to return the bribe $b$ and pay the increased fine $2 F_{S}$, hence his willingness to pay will be up to $2 F_{S}+b$. As long as $2 F_{S}+b>b+\pi$, that is, as long as $2 F_{S}>\pi$ the bribe competition will be won by $S$ who will not be convicted; the opposite happens when $2 F_{S}<\pi$.

Corruption of law enforcers tends to be more harmful to the functioning of $\mathrm{BP}$ and MBP than an exogenous enforcement costs $C$. The sanctions for accepting harassment bribes $\left(2 F_{S}\right)$ need to be large to deter bribe taking in the first place. But if $2 F_{S}$ is larger than the cost $\pi$ law enforcers incur in lying, $S$ will win the bribing game and $E$ thus would not report to start with.

\section{B. Bureaucratic Appeal}

Suppose it is possible to complain to $S$ 's supervisor about not receiving a licence but that doing so carries an expected cost $T$. Then corruption will only occur if $b<T$. As corruption 
is observed, it appears reasonable to assume that this is the case, and as long as $T>b$ all previous conclusions go through. The only difference is that when both $T$ and $C$ are large but can be reduced a some cost, it may be cheaper to fight corruption by reducing $T$ rather than $C$. This effect is analogous to that of a fall in $c$.

\section{Legalizing Bribe Taking}

What about the reverse of BP: bribe taking is legal (like tips), while sanctions against bribe paying are doubled? While most of our qualitative conclusions would apply to this alternative scheme, bribe takers would have less incentives to report than bribers because they do not have a bribe to recover. When $c>0$, the incentive to report could be the ability to get away with the bribe payment without incurring the cost of handing the licence, but that would appear to provide an odd incentive given that handing the licence is their very job. Moreover, if $S$ is a longrun player, reporting would undermine his reputation and ability to obtain bribes in the future. Hence, a scheme directed to the bribe taker would arguably need reinforcement by additional rewards over and above the allowance to keep the bribe awarded by legalization of bribe taking.

A better alternative, analogous to leniency in antitrust, may be a scheme open to both briber and bribed, where immunity is awarded only to the first party that reports, while the other party will incur stronger sanctions. In the absence of additional rewards such a scheme would likely bite mainly on the side of the briber for the reasons discussed above, but incentives to report will be amplified on both sides by the risk that the counterparty would report first. ${ }^{28}$

\section{Retaliation: Long-Run S, Long-Run E}

There are situations where $S$ has the possibility to retaliate against $E$ after she reports. Also, one may conceive situations where both $E$ and $S$ are long-run players, effectively playing a repeated game. For example, short-run E's may be represented by a long-run intermediary; or licences may need to be regularly renewed; or the long-run $S$ may be in charge of several different services needed by a long-run $E$. What would happen if also $E$ is a long-run player?

28. The possibility that the other party reports may reduce trust between corrupt partners and strengthen the effectiveness of the reporting scheme. Spagnolo (2004) develops theoretical arguments in this direction and Bigoni et al. (2012b) offer experimental evidence consistent with them.
Clearly the possibility that $S$ retaliates will reduce the attractiveness of reporting for $E$ and with it the effectiveness of the policy. In a sense, the risk of retaliation can be seen as a component of the reporting costs $C$, and our model already told us that with a high $C$ these proposed policies are likely to be ineffective (or to have some effects only for very large bribes).

When both $S$ and $E$ are long-run players this effect is multiplied and usual folk theorem arguments kick in: if discount rates are large enough "anything can happen" (irrespective of $c$ ). In this sense, BP/MBP would lose its teeth in terms of deterrence. Fighting corrupt exchanges between two patient long-run players will require more powerful incentives/policy instruments, such as large monetary rewards. ${ }^{29}$

This is not to say that these policies would be irrelevant. If bilateral repetition prevents BP/MBP from deterring bribery, then Drèze's concerns about moral and legal costs apply. As corruption is not deterred but bribe paying made legal, entrepreneurs that were not paying bribes before $\mathrm{BP} / \mathrm{MBP}$ was introduced (because they find it immoral, or too risky) may now decide to pay bribes. As discussed in Section III(C), these potential drawbacks can be avoided by modifying BP, turning into a leniency policy MBP; bribe payers obtain amnesty and get their bribe back only if they self-report. This conditional amnesty does not legalize bribe paying, so Drèze's concerns about moral costs and the risk of being convicted without any report do not apply.

Retaliation and repeated play, however, may be reduced considerably by policies that require replacing/transferring civil servants to different tasks when they are under investigation for accepting bribes. These policies are costly and may also be manipulated (false reporting may be a way to get rid of tough civil servants), but they may be necessary as complements of leniencybased reporting scheme, together with other tools against bureaucratic abuse like competition among civil servants (Shleifer and Vishny 1993).

\section{E. Additional Variations}

Reflecting on the nature of our exercise, we wish to note in this section that there are

29. Rewarding self-reporting to destabilize collusive/corrupt relationships was first proposed and studied theoretically in Spagnolo (2004). Experimental evidence on its effectiveness is reported in Apesteguia et al. (2007), Bigoni et al. (2012a), and Abbink and Wu (2013). 
millions of ways to model details. Abstractions and specific assumption just have to be made. While we have tried to provide ample commentary and motivation throughout, it is inevitable that we failed to explicitly deal with every conceivable angle and each reader (as we discovered with many referees) will probably have their pet related insights. Just to indicate, consider the following issues that one very helpful referee brought up, and which we are happy to acknowledge. We feel that most would be unlikely to affect main conclusions in major ways had we dealt with them explicitly, but we have not explored these issues in depth and maybe some of them can stimulate further research:

How would heterogeneity of $v$ and $C$ across short-run $E$ 's affect predictions? What would happen if offering or asking for bribes were illegal, irrespective of whether a bribe is subsequently exchanged? The given payoffs presume that reported bribes have verifiable amounts (that are confiscated, or given back); what would happen otherwise? What if $\alpha$ differs across players and also $S$ may suffer moral costs of bribery?

Also, we assumed our parameters to be independent and conducted comparative statics by varying them. In many relevant situations some of these parameters will be highly correlated. We feel that our model with independent parameters may still partly capture these environments, as we can perform thought experiments with multiple parameters moving together (we do a bit of this in the conclusions). ${ }^{30}$

\section{F. Empirical Tests}

The issue of evaluating BP/MBP is not entirely hypothetical, as analogous provisions have been in place in several European countries, and in particular in China since 1997. However, based on archival data, there is hardly any

30. One last important caveat, already flagged in footnote (i). We followed Basu in disregarding the possibility of "double crossing," that is, of governance problems in the corrupt transaction. This is okay in the environment Basu described, where a bribe and a license can be exchanged simultaneously. When we start focusing on other forms of corruption, however, for example, involving construction projects or complex procurements, part or all of $S$ 's corrupt task may take time and may have to be performed before, after or elsewhere relative to the payment of the bribe (or the first bribe). To fully capture these more complex situations, the enforcement of the exchange must be endogenized. Then policies as studied in this article may end up having surprisingly different implications (see Buccirossi and Spagnolo 2006). conclusive empirical evidence regarding their effects. $^{31}$

A promising approach may be to run experiments. The last decade saw a burst of interest in experimental studies of aspects of corruption (see, e.g., Serra and Wantchekon 2012). A recent intriguing laboratory study by Abbink et al. (2014) evaluates BP/MBP and shows it may reduce corruption, but retaliation by bribe takers can hamper the effect. Abbink et al.'s design is not tailored to test our theory (in particular, they have no counterpart to our $c$ ). However, their findings about retaliation suggest that the issues surrounding $C$ in our theory (cf. Section III) are a real worry. Inclination by $S$ to retaliate would be one reason for $C$ to be high. ${ }^{32}$

Apropos the leniency policy we advocated (Section III.C), it is worth noting that having theoretically appealing properties is not its only advantage. There is also some empirical evidence about the effectiveness (and drawbacks) of leniency policies from closely related contexts. ${ }^{33}$

\section{CONCLUSIONS}

Rather than repeat all pros and cons of BP, let us sketch key insights with broad strokes. We concentrate on the arguably empirically most relevant scenario, where a long-run civil servant $(S)$ interacts with a sequence of one-shot entrepreneurs $(E)$. BP then carries significant merit, and taking into account various considerations, such as moral constraints and costs of getting justice, a modified proposal, MBP, where bribe givers who report get immunity

31. A Financial Times blog post by Xingxing Li (10:50 a.m., May 1, 2012) argues the Chinese policy worked poorly; however, to draw that conclusion with confidence one needs a counterfactual, which appears lacking; http://blogs.ft.com/beyond-brics/2012/05/01/guest-postbribery-and-the-limits-of-game-theory-the-lessons-fromchina/\#).

32. An even less closely related recent experiment by Engel, Goerg, and Yu $(2013,20)$ compares "symmetric versus asymmetric punishment regimes for bribery" and concludes inter alia that "if bribes are punished more leniently, there is more corruption." However, this does not really say anything about BP because the setting involves positive fines for both parties, not legal bribe giving plus repaid fines. Moreover, the game explored is very different from ours in that it allows the bribed party to nevertheless not provide the demanded service.

33. See Miller (2009) for market data regarding cartels, and Apesteguia, Dufwenberg, and Selten (2007), Hinloopen and Soetevent (2008), and Bigoni et al. (2012a) for experimental evidence. For recent evidence of success against mafia-related crime, see Acconcia et al. (2013). 
from fines, does even better. The following table summarizes:

\begin{tabular}{lcc}
\hline $\begin{array}{l}\text { BP/MBP with } \\
\text { long-run } \boldsymbol{S}\end{array}$ & $\boldsymbol{c}>\mathbf{0}$ & $\boldsymbol{c}<\mathbf{0}$ \\
\hline High $C / v($ or $C / b)$ & Ineffective & Ineffective \\
Low $C / v($ or $C / b)$ & Bribes $\downarrow$, Licences $\downarrow$ & Bribes $\downarrow$, licences $\uparrow$ \\
\hline
\end{tabular}

Recalling, the higher is the efficiency of a country's legal institutions, the lower is $C$, the cost of reporting bribery. The higher is the efficiency of the public service, the lower is $c$, the cost to a civil servant to deliver a licence. The table depicts $C$ and $c$ separately; one should bear in mind that in reality they may be correlated, as they both tend to be related to "state capacity." 34 $v$ is the value of the task $S$ should perform and the upper bound on bribes $(b<v)$. A high $C / v$, or $C / b$, can either be due to poor legal institutions or to a low value of a licence/bribe.

The table clarifies in which institutional contexts these proposals are likely to be effective, and the most urgent complementary policies needed where the status quo would make them ineffective. When the legal system is efficient and bribes sizable because licences are highly valuable, then $\mathrm{BP} / \mathrm{MBP}$ is effective in deterring bribes. However, if the public administration is inefficient, to the point that $c>0$, in the absence of other policy changes BP/MBP leads to licences not being delivered. It would then be desirable to complement these policies by a reform of the public administration that reduces $c$. When, instead, the public administration is efficient, to the point where $c<0$, the policy may have unambiguously positive impact. This effect is limited to "grand corruption" when the legal system is inefficient, but extends to all sizes of bribes when also the legal system is efficient.

$\mathrm{BP} / \mathrm{MBP}$ is likely to be ineffective when the legal system is very inefficient or for lowvalue harassment bribes/licences (aka "speed money," akin to tips). In such cases, the priority should be to reduce $c$ and $C$. Fighting corruption in countries with weak institutions is likely to require a set of complementary policies that accompany revelation schemes like BP or MBP, measures aimed at improving civil service performance and the accountability of law enforcement institutions. ${ }^{35}$

34. See for example, Besley and Persson (2010).

35. This is in the spirit of Mookherjee and Png (1995). They analyze an inspection-corruption game and show that if government can use other instruments to induce inspectors to perform (stricter monitoring, higher efficiency wages, and
Some recent initiatives illustrate the feasibility of policies with potential to move $c$ or $C$. Consider, for example, the following customer satisfaction feedback system recently implemented in the Jhang district of Punjab, as described in The Economist (September $24,2009):{ }^{36}$

\begin{abstract}
Zubair Bhatti, a Pakistani bureaucrat, asked all clerks in the Jhang district who handled land transfers to submit a daily list of transactions, giving the amount paid and the mobile-phone numbers of the buyer and the seller. He explained that he would be calling buyers and sellers at random to find out whether they had been asked to pay any extra bribes or commissions. When charges were subsequently brought against a clerk who had asked for a bribe, the others realized that Mr Bhatti meant business, and buyers and sellers reported a sudden improvement in service. Mr Bhatti extended the scheme to other areas, such as cracking down on vets who demanded bribes from farmers, and has proposed that the Jhang model [ ...] be adopted in other districts.
\end{abstract}

The scheme may reduce $c$ (customer satisfaction information is used to sharpen bureaucrats' incentives) and $C$ (can become a special protected channel for whistleblowing). Another example is Björkman and Svensson's (2009) field experiment documenting positive effects of village meetings on health service provision; this transparency/disclosure policy arguably reduced $c$.

Basu restricted attention to harassment bribes. He did not tackle distortive corruption where third parties are hurt, yet our analysis suggests that these instruments may be even more useful in such settings. However, for BP/MBP to be politically and ethically viable to fight distortive corruption, complementary policies beyond those that move $C$ and $c$ may need to be in place. It may be necessary to reward whistleblowers for their opportunity costs of reporting, as done by U.S. whistleblower programs against federal fraud, tax evasion, and financial misconduct. These rewards must only cover briber's private valuation of the object acquired, not the negative externalities generated.

tougher sanctions) and has an unlimited budget, then one can find an equilibrium without bribes that welfare dominates one with. In such a world, BP/MBP would increase welfare by facilitating corruption deterrence.

36. We thank Husnain Ahmad for alerting us to the Jhang model. Read more about it at: punjabmodel.gov.pk 


\section{REFERENCES}

Abbink, K., and K. Wu. "Reward Self-Reporting to Deter Corruption: An Experiment on Mitigating Collusive Bribery." Discussion Paper 42/13, Department of Economics, Monash University, 2013.

Abbink, K., U. Dasgupta, L. Gangadharan, and T. Jain. "Letting the Briber Go Free: An Experiment on Mitigating Harassment Bribes." Journal of Public Economics, 111, 2014, 17-28

Acconcia, A., G. Immordino, S. Piccolo, and P. Rey. "Accomplice-Witness and Organized Crime: Theory and Evidence from Italy." CEPR Discussion Papers 9543, 2013

Apesteguia, J., M. Dufwenberg, and R. Selten. "Blowing the Whistle." Economic Theory, 31, 2007, 143-66.

Banerjee, A., R. Hanna, and S. Mullainathan. "Corruption," in Handbook of Organizational Economics, Chapter 27, edited by R. Gibbons and J. Roberts. Princeton: Princeton University Press, 2013, 1109-47.

Basu, K. "Why, for a Class of Bribes, the Act of Giving a Bribe Should Be Treated as Legal." Working Paper 172011 DEA, Ministry of Finance, Government of India, 2011.

Basu, K., S. Bhattacharya, and A. Mishra. "Notes on Bribery and the Control of Corruption." Journal of Public Economics, 48, 1992, 349-59.

Bertrand, M., S. Djankov, R. Hanna, and S. Mullainathan. "Obtaining a Driver's Licence in India: An Experimental Approach to Studying Corruption." Quarterly Journal of Economics, 122, 2007, 1639-76.

Besley, T., and T. Persson. "State Capacity, Conflict and Development." Econometrica, 78, 2010, 1-34.

Bigoni, M., S.-O. Fridolfsson, C. LeCoq, and G. Spagnolo. "Fines, Leniency and Rewards in Antitrust." RAND Journal of Economics, 43, 2012a, 368-90.

. "Trust and Deterrence." CEPR Discussion Paper No. 9002, 2012b

Björkman, M., and J. Svensson. "Power to the People: Evidence from a Randomized Field Experimen of Community-Based Monitoring in Uganda." Quarterly Journal of Economics, 124, 2009, 735-69.

Buccirossi, P., and G. Spagnolo. "Leniency Policies and Illegal Transactions." Journal of Public Economics, 90, 2006, 1281-97.
Della Porta, D., and A. Vannucci. The Hidden Order of Corruption. Advances in Criminology. Farnham, UK; Burlington, VT: Ashgate, 2012.

Drèze, J. "The Bribing Game." Indian Express, April 23, 2011.

Engel, C., S. J. George, and G. Yu. "Symmetric vs. Asymmetric Punishment Regimes for Bribery." Working Paper of the Max Planck Institute for Research on Collective Goods, Bonn 2012/1, 2013.

Fudenberg, D., D. Kreps, and E. Maskin. "Repeated Games with Long-Run and Short-Run Players." Review of Economic Studies, 57, 1990, 555-73.

Hinloopen, J., and A. Soetevent. "Laboratory Evidence on the Effectiveness of Corporate Leniency Programs." RAND Journal of Economics, 39, 2008, 607-16.

Hunt, J. "How Corruption Hits People When They Are Down." Journal of Development Economics, 84, 2007, 574-89.

Miller, N. "Strategic Leniency and Cartel Enforcement." American Economic Review, 99, 2009, 750-68.

Mookherjee, D., and I. P. L. Png. "Corruptible Law Enforcers: How Should They Be Compensated?" The Economic Journal, 105, 1995, 145-59.

Oak, M. "Legalization of Bribe Giving When the Bribe Type Is Endogenous." Research Paper No. 2013-06, School of Economics, The University of Adelaide, 2013.

Olken, B., and R. Pande. "Corruption in Developing Countries." Annual Review of Economics, 4, 2012, 479-505.

Serra, D., and L. Wantchekon, ed. New Advances in Experimental Research on Corruption. Research in Experimental Economics, Vol. 15. Bingley, UK: Emerald Group Publishing, 2012

Shleifer, A., and R. Vishny. "Corruption." Quarterly Journal of Economics, 108, 1993, 599-617.

Spagnolo, G. "Divide et Impera: Optimal Leniency Programs." CEPR Discussion Paper No. 4840, 2004.

- "Leniency and Whistleblowers in Antitrust", in Handbook of Antitrust Economics, edited by P. Buccirossi. Cambridge, MA: MIT Press, 2008.

Svensson, J. "Eight Questions about Corruption." Journal of Economic Perspectives, 19, 2005, 19-42. 